\title{
Antinociceptive Effects of AGAP, a Recombinant Neurotoxic Polypeptide: Possible Involvement of the Tetrodotoxin-Resistant Sodium Channels in Small Dorsal Root Ganglia Neurons
}

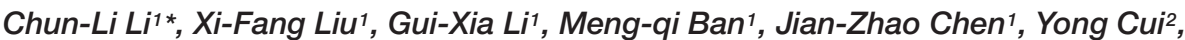 \\ Jing-Hai Zhang ${ }^{2}$ and Chun-Fu Wu ${ }^{1 *}$
}

'Department of Pharmacology, Shenyang Pharmaceutical University, Shenyang, China, ${ }^{2}$ Department of Biochemistry, Shenyang Pharmaceutical University, Shenyang, China

OPEN ACCESS

Edited by:

Chiranjiib Chakraborty,

Galgotias University, India

Reviewed by:

Pascal Darbon,

University of Strasbourg, France Alexander Oksche

Mundipharma Research, Germany

*Correspondence:

Chun-Li Li

lichunli_2014@126.com

Chun-Fu Wu

wucf@syphu.edu.cn

Specialty section:

This article was submitted to Experimental Pharmacology and Drug

Discovery,

a section of the journal

Frontiers in Pharmacology

Received: 27 June 2016 Accepted: 02 December 2016 Published: 20 December 2016

Citation:

Li C-L, Liu X-F, Li G-X, Ban M-q, Chen J-Z, Cui Y, Zhang J-H and Wu C-F (2016) Antinociceptive Effects of AGAP, a Recombinant Neurotoxic Polypeptide: Possible

Involvement of the Tetrodotoxin-Resistant Sodium Channels in Small Dorsal Root Ganglia Neurons.

Front. Pharmacol. 7:496. doi: 10.3389/fphar.2016.00496
Antitumor-analgesic peptide (AGAP) is a novel recombinant polypeptide. The primary study showed that AGAP $1.0 \mathrm{mg} / \mathrm{kg}$ exhibited strong analgesic and antitumor effects. The tail vein administration of AGAP potently reduced pain behaviors in mice induced by intraplantar injection of formalin or intraperitoneal injection of acetic acid, without affecting basal pain perception. To further assess the mechanisms of AGAP, the effects of AGAP on sodium channels were assessed using the whole-cell patch clamp recordings in dorsal root ganglia (DRG) neurons. The results showed that AGAP (3-1000 nM) inhibited the sodium currents in small-diameter DRG neurons in a dosedependent manner. 1000 nM AGAP could inhibit the current density-voltage relationship curve of sodium channels in a voltage-dependent manner and negatively shift the activation curves. 1000 nM AGAP could reduce the tetrodotoxin-resistant (TTX-R) sodium currents by $42.8 \%$ in small-diameter DRG neurons. Further analysis revealed that AGAP potently inhibited Nav1.8 currents by $59.4 \%$, and negatively shifted the activation and inactivation kinetics. $1000 \mathrm{nM}$ AGAP also reduced the Nav1.9 currents by $33.7 \%$, but had no significant effect on activation and inactivation kinetics. Thus, our results demonstrated that submicromolar concentrations of AGAP inhibited TTX$R$ sodium channel in rat small-diameter DRG neurons. It is concluded that these new results may better explain, at least in part, the analgesic properties of this polypeptide.

Keywords: Voltage-gated sodium channels, Nav1.8, Nav1.9, pain, scorpion toxins

\section{INTRODUCTION}

Asian scorpion Buthus martensii Karsch, widely distributed in Mongolia, Korea, and China, has been one of the indispensable materials used in Chinese traditional medicine for thousands of years. In China, scorpions and their tissues have been extensively used for treatment of analgesia, inflammatory, epilepsy, convulsion, anticancer, and so on. It is well known that scorpion venom is complex mixture substances. It is a particularly rich source interacting specifically with various ion channels in excitable cell membranes. Proteins from Scorpion venom modes of action fall within two major categories: one is pore-blocking proteins which block the movement of ions and the other alters the conformation of ion channel and also the 
statement of ion channel, such as open, closed or activation (Lai et al., 2004).

Scorpion polypeptides have long chain and short chain peptides. In 2003, the expression and purification of a novel antitumor-analgesic peptide (AGAP) were reported in E. coli (Herzog et al., 2001). BmK AGAP is a typical long-chain scorpion toxin, which is composed of 66 amino acids cross-linked by four disulfide bridges (Cys12-Cys63, Cys16-Cys36, Cys22-Cys46, and Cys26-Cys48). The gene cloning (GenBank No. AF464898), protein expression, and characterization of the encoding gene of this peptide have been investigated (Liu et al., 2003). The primary study showed that AGAP exhibited strong analgesic and antitumor effects, but the analgesic mechanisms remain unclear in VGSCs (Liu et al., 2003).

Voltage-gated sodium channels mediate the inward sodium current and are critical for the initiation and propagation of action potentials in excitable tissues, including the brain and peripheral nerves (Payandeh et al., 2011). Nav1.3, Nav1.7, Nav1.8, and Nav1.9 have been identified as possible targets for analgesics. The development of chronic pain can be caused to peripheral nerve injury which is related to hyperexcitability of sensory neurons in DRG (Dib-Hajj et al., 2010; Ebersberger et al., 2011; Djouhri et al., 2012). At least two types of sodium currents can be recorded in small-diameter neuron of rat DRG (Caffrey et al., 1992).

Previous reports have demonstrated that TTX-R is a unique expression in the DRG neurons. Electrophysiological studies in sodium channels also have confirmed that TTX-R sodium currents may play a key role in setting the action potential conduction in the unmyelinated $\mathrm{C}$ fibers which arise from small DRG neurons (Jeftinija, 1994; Quasthoff et al., 1995). TTX-R sodium channels, Nav1.8 and Nav1.9, both are strongly implicated in the molecular mechanisms of nociception. In contrast to fast activating and the rapidly inactivating TTX-S channels, Nav1.8 channels exhibit $\sim 10$-fold slower kinetics of activation and inactivation, whereas Nav1.9-mediated currents are persistent current with a more hyperpolarized voltage dependence and ultraslow recovery from inactivation (Cummins et al., 1999).

Many kinds of long-chain neurotoxins which modulate sodium channels and calcium channels have been purified from scorpion venom (Valdivia et al., 1992; Tan et al., 2001). Our previous work has shown that AGAP potently inhibited voltage gated calcium channels (VGCCs), especially high-voltage activated calcium currents in rat DRG neurons (Liu et al., 2014). Here, we examined whether AGAP could attenuate pain behaviors in mice, and further assess the analgesic mechanisms of AGAP, the present study was therefore designed to evaluate the mechanisms of recombinant AGAP on the TTX-R sodium channels in rat small-diameter DRG neurons.

\section{MATERIALS AND METHODS}

\section{Animals}

Adult 6 weeks male Sprague Dawley rats (160-220 g), and Kunming mice (18-22 g) were used for the experiments. The animals were housed at room temperature $\left(23-26^{\circ} \mathrm{C}\right)$ under a 12 $\mathrm{h}$ light/dark cycle with ad libitum access to food and water. All procedures were carried out in accordance with the Committee Ethics of Animal Experiments of the Shenyang Pharmaceutical University.

\section{Behavioral Analysis \\ Acetic Acid-Induced Writhing Test}

The male mice were treated with AGAP $(0.25,0.5,1.0 \mathrm{mg} / \mathrm{kg})$, the reference antinociceptive drug morphine $(2 \mathrm{mg} / \mathrm{kg})$, or saline as a negative control ( $n=12$ per group). The methods included randomization and blinding in all vivo experiments. Acetic acid $(0.8 \% \mathrm{v} / \mathrm{v}, 10 \mathrm{ml} / \mathrm{kg})$ was injected intraperitoneally, and the mice were placed in a plastic cage. The abdominal writhes were defined as extensions of the abdomen with outstretching of the hind limbs. The intensity of pain was quantified by counting the number of writhes occurring for $30 \mathrm{~min}$ after acetic acid injection.

\section{Hot Plate Test}

The hot plate was an electrically heated surface kept at a constant temperature of $55.0 \pm 0.5^{\circ} \mathrm{C}$. Female mice ( $n=12$ per group) were placed on the heated surface, and the latency of pain (jumping or licking of the paws) was recorded at $0,30,60,90$, and 120 min after drug administration, whereupon the reaction time of $0 \mathrm{~min}$ is the start of the test. As previous researches indicated, $2 \mathrm{mg} / \mathrm{kg}$ morphine offered an ideal analgesic effect in the visceral pain test (Meymandi and Keyhanfar, 2013), while in the hot plate test, morphine couldn't elicit significant analgesic effects at low dosages until we raised the dosage to $5 \mathrm{mg} / \mathrm{kg}$ (Casarrubea et al., 2012; Araújo et al., 2016). Morphine (5.0 $\mathrm{mg} / \mathrm{kg}$ ) was used as the reference drug. Antinociceptive effects of AGAP and morphine were compared in dose-response and time course experiments. A cut-off time of $60 \mathrm{~s}$ was chosen to indicate complete analgesia in order to avoid potential harmful effects. The latencies of pain were recorded for each animal (Yamamoto et al., 2002).

\section{Formalin Test}

Formalin test was performed in male mice as Rosa et al. (2008) described. Formalin solutions were prepared at $5 \%$ in saline from a formalin stock and injected intraplantarly to the left hind paw in a volume of $20 \mu \mathrm{l}$. AGAP at concentrations ranging from 0.25 to $1.0 \mathrm{mg} / \mathrm{kg}$ was administered intravenously $20 \mathrm{~min}$ before formalin injection. Morphine was administered at a dose of $2 \mathrm{mg} / \mathrm{kg}$ ( $n=12$ per group). $30 \mathrm{~min}$ before formalin injection. After the formalin injection, mice were immediately placed in a clear, transparent box $(11 \mathrm{~cm} \times 11 \mathrm{~cm} \times 16 \mathrm{~cm})$ with a mirror placed underneath at a $45^{\circ}$ angle to view the animals' paws completely. Then, mice were observed for $30 \mathrm{~min}$ after the formalin injection, the times of licking or flinching the injected hind paw from 0 to $5 \mathrm{~min}$ (first phase) and from 15 to $30 \mathrm{~min}$ (second phase) was recorded as indicative of nociception.

\section{Rotarod Test}

Fine motor coordination and learning was assessed by using the rotarod test (Munro, 2009). A control (saline) group and AGAP group (treated $1.0 \mathrm{mg} / \mathrm{kg} ; n=10$ ) were utilized. The fall-off latency to the first fall was recorded. 


\section{Immunohistochemistry}

Rats were deeply anesthetized, and the $\mathrm{L}_{4-6}$ lumbar DRG were removed quickly from the spinal cord, fixed with $4 \%$ paraformaldehyde in $0.1 \mathrm{M}$ phosphate buffer overnight at $4^{\circ} \mathrm{C}$. After the tissues embedded by paraffin, a series of $5 \mu \mathrm{m}$ thick sections were cut for immunohistochemistry. Primary antibodies targeting rat $\mathrm{Na}_{V} 1.8$ (1:200; Alomone), $\mathrm{Na}_{V} 1.9$ (1:200; Alomone) and NF200 (1:200; Sigma) were performed for immunohistochemistry overnight at $4^{\circ} \mathrm{C}$. After washing three times with PBST, the sections were incubated with secondary antibodies (1:100; sigma) for $1 \mathrm{~h}$ at $37^{\circ} \mathrm{C}$. Fluorescent images were captured in an Olympus BX40 microscope (Olympus, Tokyo, Japan).

\section{Preparation of DRG Neurons Primary Neuronal Cultures}

$\mathrm{L}_{4-6}$ DRG tissue was removed from day 1-3 rat pups in $\mathrm{Ca}^{2+}$ and $\mathrm{Mg}^{2+}$ free Hank's, minced, and incubated for $15 \mathrm{~min}$ at $37^{\circ} \mathrm{C}$ in enzyme solutions containing trypsin and collagenase. The tissue was triturated in culture medium containing 1:1 DMEM/F-12, $10 \%$ fetal calf serum, $5 \%$ horse serum, $1.5 \mathrm{mg} / \mathrm{ml}$ bovine serum albumin, $100 \mathrm{U} / \mathrm{ml}$ penicillin and $0.1 \mathrm{mg} / \mathrm{ml}$ streptomycin and plated (600-800 cells $\left./ \mathrm{mm}^{2}\right)$ on glass coverslips coated with PolyL-Lysine. The cells were maintained at $37^{\circ} \mathrm{C}$ in a humidified $95 \%$ air $/ 5 \% \mathrm{CO}_{2}$ incubator overnight, and studied with whole-cell patch-clamp techniques after short-term culture (12-24 h).

\section{DRG Neurons Acutely Isolated}

Preparation of DRG neurons was established as described previously (Yu et al., 2011). Briefly, SD rats weighing about $150 \mathrm{~g}$ (6 weeks of age) were deeply anesthetized, $\mathrm{L}_{4-6}$ DRG neurons were dissociated using enzyme digestion as previously described with slight modifications. The cells were then triturated and plated onto acid-washed coverslips that had been coated previously with $0.01 \%$ poly-L-lysine. Media consisted of Dulbecco's Modified Eagle Medium/Ham's F12 medium (DMEM/F12) supplemented with $10 \%(\mathrm{v} / \mathrm{v})$ heat-inactivated horse serum and $10 \%(\mathrm{v} / \mathrm{v})$ fetal bovine serum. Cell densities at plating were $800-1000$ cells $/ \mathrm{ml}$. The cells were maintained at $37^{\circ} \mathrm{C}$ in a humidified $95 \%$ air $/ 5 \% \mathrm{CO}_{2}$ incubator and were studied between $2-12 \mathrm{~h}$ after removal from the animal.

\section{Electrophysiological Recordings}

Voltage-gated sodium currents of $\mathrm{L}_{4-6}$ DRG neurons were recorded in the whole-cell configuration of the patch clamp method (Li et al., 2010). During experiments, membrane potential and currents were recorded from small-diameter DRG neurons using the whole-cell patch clamp technique under visual control with Nikon TE2000-U inverted microscope. Patch-clamp electrodes were pulled with a P-97 puller, and had a resistance of 3-5 M . The experiment of whole-cell patch clamp was carried out using an AxoPatch 200B amplifier (Axon Instruments, Foster City, CA, USA); all signals were low pass filtered at $1.5 \mathrm{kHz}$ and the sampling rate was $10 \mathrm{kHz}$, then sampled data were stored digitally on a computer for further analysis. The pipette solution contained (in $\mathrm{mM}$ ): $100 \mathrm{CsCl}, 30 \mathrm{CsF}, 8 \mathrm{NaCl}, 2.4 \mathrm{CaCl}_{2}$, $1 \mathrm{MgCl}_{2}$, 5 EGTA, $4 \mathrm{Na}_{2}$ ATP, 10 HEPES, 0.4 GTP (pH 7.3,
Osmolarity is $290-300 \mathrm{mOsm}$ ). The bathing solution contained (in $\mathrm{mM}$ ): 100 choline chloride, $40 \mathrm{NaCl}, 3 \mathrm{KCl}, 2.5 \mathrm{CaCl}_{2}, 1$ $\mathrm{MgCl}_{2}, 10$ HEPES, 10 glucose, $0.005 \mathrm{LaCl}_{3}$ (pH 7.4, Osmolarity is $290-300 \mathrm{mOsm}$ ), supplemented with $1 \mu \mathrm{M}$ TTX when the currents of TTX-R, $\mathrm{Na}_{V} 1.8$ and $\mathrm{Na}_{V} 1.9$ channel were recorded. The pipette offset was used to back the liquid junction potential to zero before patch formation. Capacitive transients and series resistances were compensated electronically by $70-80 \%$. After seal formation and membrane rupturing, the cells were allowed to stabilize for $3 \mathrm{~min}$ before rupturing the pulse protocols. All experiments were carried out at room temperature $\left(23 \pm 2^{\circ} \mathrm{C}\right)$.

\section{Reagents}

$\mathrm{CsCl}$, CsF, TTX, $\mathrm{LaCl}_{3}$, HEPES, Poly-L-lysine, EGTA, $\mathrm{Na}_{2} \mathrm{ATP}$, and GTP were purchased from Sigma-Aldrich, whereas DMEM/F12, horse serum, and fetal bovine serum were from Gibco. Penicillin and streptomycin were purchased from Invitrogen. AGAP was synthesized by the laboratory of Dr. Zhang Jinghai.

Stock solutions of AGAP were prepared in physiological saline and diluted in assay buffer immediately before use. AGAP was dissolved in the bath solution. Throughout the experiment, bath or AGAP solutions were delivered to the DRG neurons via a fast gravity-driven perfusion system. The doses of AGAP were determined by the preliminary experiments in vivo or vitro experiment.

\section{Data Analysis}

\section{The Dose-Response Curves}

The dose-response curves for AGAP was determined from a curve fit of the Hill equation to the data points: $f=$ $1 /\left\{1+\left(I C_{50} /[A G A P]\right)^{\mathrm{nH}}\right\}$, where $f$ is the fractional current block at the test potential, $\mathrm{nH}$ is the Hill coefficient, and [AGAP] is the concentration of AGAP. The inhibition effect calculated as the mean reduction of maximum peak amplitude.

\section{Establish Voltage-Dependent Steady-State Activation Curves}

The voltage dependence of activation was determined using standard protocols. The conductance $G(V)$ was calculated according to $G=I /\left(V-V_{\mathrm{Na}}\right)$, where $V_{\mathrm{Na}}$ is the reversal potential, $V$ is the test pulse potential and $I$ is the current amplitude. Normalized peak conductance was fitted by the following Boltzmann equation: $G / G_{\max }=1 /\left\{1+\exp \left[\left(V_{1 / 2}-V\right) / k\right]\right\}$, where $G_{\max }$ is the maximum conductance, $V_{1 / 2}$ is the membrane potential of half-maximal activation and $k$ is the slope factor.

\section{Establish Voltage-Dependent Steady-State Inactivation Curves}

Steady state inactivation curves were determined with a Boltzmann fit of the data using: $I / I_{\max }=1 /\left\{1+\exp \left[\left(V-V_{1 / 2}\right) / k\right]\right\}$, where $I$ is the current amplitude, $I_{\max }$ is the maximal current amplitude, $V$ is the prepulse, $V_{1 / 2}$ is the prepulse voltage at which the current amplitude is half maximum, and $k$ is the slope factor. 
The voltage-clamp data were digitized and analyzed using pClamp 10.0 software (Axon Instruments). Multiple comparisons were evaluated by one-way ANOVA followed by Tukey's test, two-way ANOVA or repeated-measure two-way ANOVA followed by Bonferroni test. When only two groups were compared, an unpaired $t$-test was used. Data were expressed as mean \pm standard error of mean (SEM). $P<0.05$ indicated statistically significant differences.

\section{RESULTS}

\section{Effects of AGAP on Acetic Acid-Induced Abdominal Writhing Visceral Pain}

We first tested the effects of intravenously administered AGAP to reduce pain-related behaviors after intraperitoneal administration of $0.8 \%$ acetic acid. As shown in Figure 1, intraperitoneal administration of acetic acid induced significant abdominal writhing in mice. When mice were pretreated with AGAP, we observed significant dose-dependent effect of AGAP $(0.5-1.0 \mathrm{mg} / \mathrm{kg})$ on acetic acid-induced writhing relative to vehicle-treated mice. In order to compare the antinociceptive effect of AGAP, a group of mice were administered with morphine. The results showed that $2.0 \mathrm{mg} / \mathrm{kg}$ morphine also significantly reduced the total number of writhes. Inhibition ratio of writhes is 69.8 and $60.2 \%$ after administration of AGAP $(1.0 \mathrm{mg} / \mathrm{kg})$ and morphine $(2.0 \mathrm{mg} / \mathrm{kg})$, respectively $(P<0.001$ and $P<0.01$, respectively, $n=12$ in each group).

\section{Effects of AGAP on the Hot Plate-Induced Nociception}

To complement and extend our in vivo studies, the antinociceptive effects of AGAP were studied in the hot

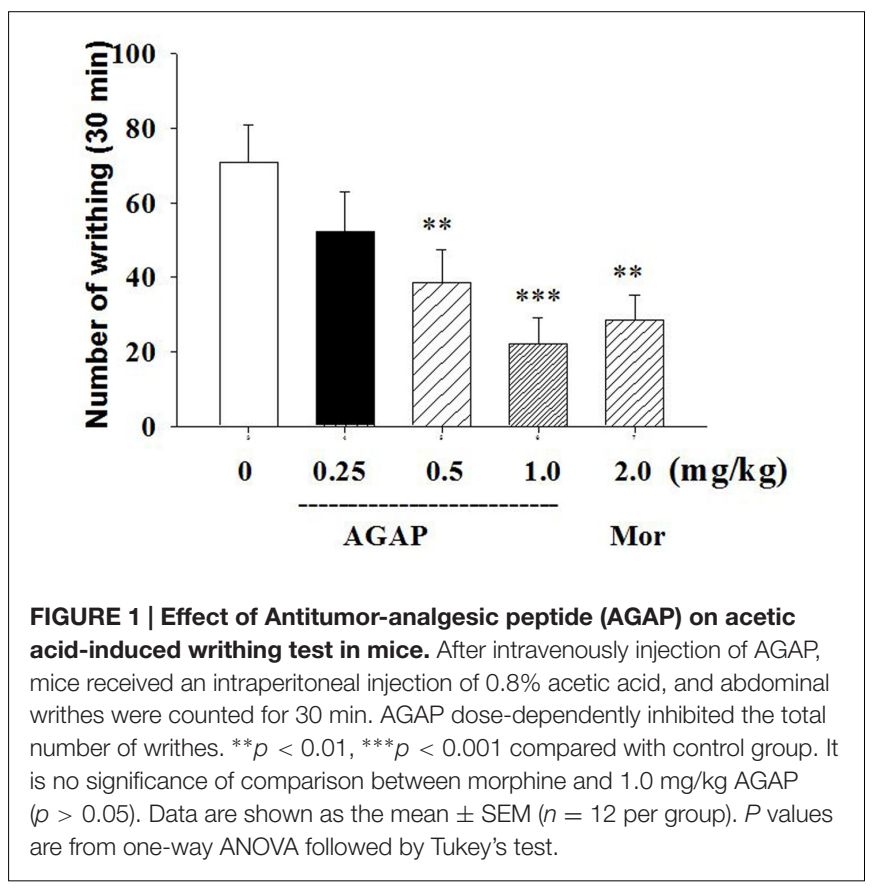

plate test in mice. AGAP was injected into the caudal vein of mice, the physiological saline was a control, and the pain latency was recorded. On the hot plate assay, AGAP $(0.5-1.0 \mathrm{mg} / \mathrm{kg})$ significantly increased the response latency compared with the control group (Figure 2). The observed pharmacological action was similar to morphine $(5.0 \mathrm{mg} / \mathrm{kg})$. The latency did not return to baseline within $120 \mathrm{~min}$ for test.

\section{Effects of AGAP on Formalin-Induced Nociception}

To further determine whether AGAP induces analgesia effect, we examined paw licking and flinching responses to intraplantar injection of $5 \%$ formalin into the hind paw after an injection of AGAP. Formalin concentrations $>0.5 \%$ induces a biphasic response in rodents (Shields et al., 2010). AGAP resulted in a significant dose-dependent suppression of pain behaviors relative to vehicle-injected mice in both characteristic first (0-5 min) and second (15-30 $\mathrm{min})$ phases of the behavioral response to formalin (Figure 3). The inhibition rate of $1.0 \mathrm{mg} / \mathrm{kg}$ AGAP were 78.2 and $81.5 \%$ for the first phase and second phase of formalin response, respectively ( $P<0.001, n=12$ in each group). The results demonstrated that the suppressive effects of AGAP were similar efficient on both phases. In order to compare the antinociceptive potency of AGAP, another group of mice ware injected with morphine. Similar to AGAP, morphine significantly inhibited pain responses of both phases after formalin injection. The analgesic effect of $1.0 \mathrm{mg} / \mathrm{kg}$ AGAP was stronger than $2.0 \mathrm{mg} / \mathrm{kg}$ morphine (Figure 3, $P<0.01, n=12$ in each group).

\section{Rotarod Test}

There were no significant differences between control group and $1.0 \mathrm{mg} / \mathrm{kg}$ AGAP. The fall-off latencies ranged from $108.64 \pm 3.98$ to $101.51 \pm 4.12$ after administration of $1000 \mathrm{nM}$ AGAP $(p>0.05, P$ values are from unpaired $t$-test, $n=10)$. The results indicated that AGAP treatments didn't impair motor function.

\section{Expression Profiles of $\mathrm{Na}_{v} 1.8$ and $\mathrm{Na}_{v} 1.9$ in DRG Neurons}

In mammals, acute pain is transmitted to the CNS mainly by two VGSCs, TTX-S Nav1.7 and TTX-R Nav1.8, which are expressed in small-diameter DRG neurons (Dib-Hajj et al., 2010). Nociceptors also express Nav1.9, a second TTX-R sodium current involved in diabetic neuropathy and inflammatory pain (Cummins et al., 1999; Ebersberger et al., 2011). We compared $\mathrm{Na}_{V} 1.8$ and $\mathrm{Na}_{V} 1.9$ localizations by double immunofluorescent labeling with NF200, a marker of large- and medium-sized neurons (Figure 4). Our results showed that Nav1.8 mainly expressed in small- and medium-sized DRG neurons that rarely contained NF200, whereas $\mathrm{Na}_{V} 1.9$ selectively expressed in smallsized DRG neurons that completely did not contain NF200. This finding is similar to preliminary reported results ( $\mathrm{Yu}$ et al., 2011; Li et al., 2015). Therefore, DRG neurons with diameters of 15-25 $\mu \mathrm{m}$ (small-sized) were selected for continued experiments. 


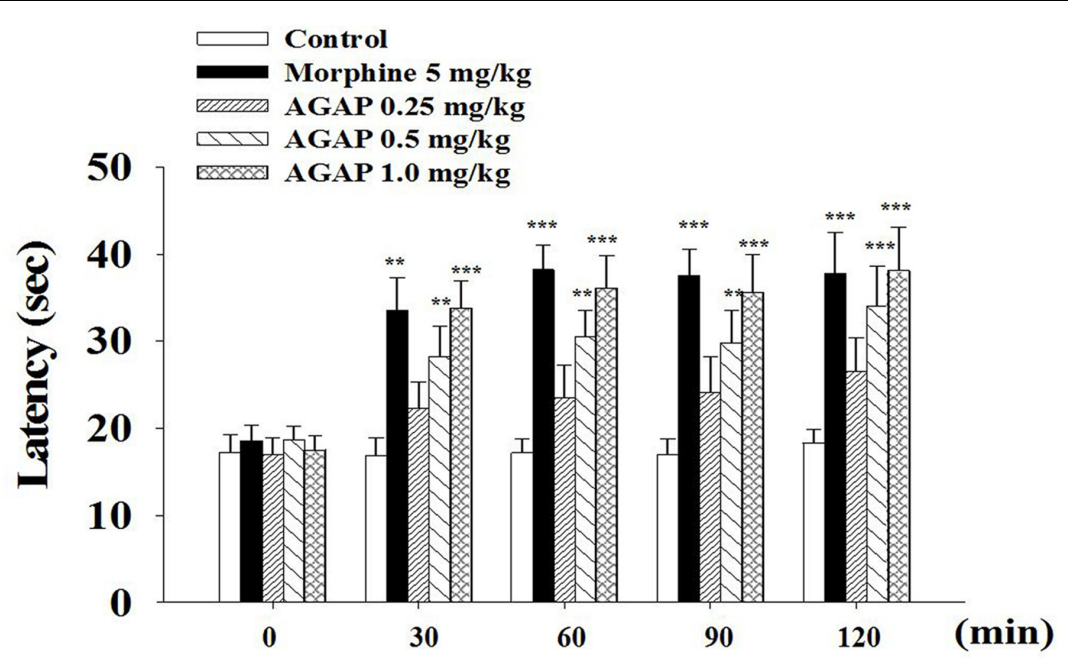

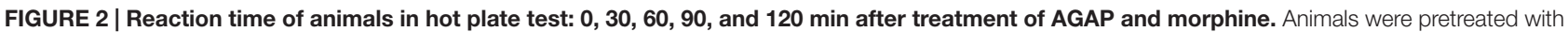
vehicle, morphine $(5 \mathrm{mg} / \mathrm{kg})$, AGAP $(0.25,0.5$, and $1.0 \mathrm{mg} / \mathrm{kg})$ prior to the tests at $55^{\circ} \mathrm{C}$. Each column represents the mean with $\mathrm{X} \pm \mathrm{SEM}$. for twelve mice in each group. The symbols denote the significance levels: ${ }^{* *} p<0.01,{ }^{* * *} p<0.001$ compared with control group. Morphine and 1.0 mg/kg AGAP were not statistical difference $(p>0.05)$. Data are shown as the mean \pm SEM $(n=12$ per group). $P$ values are from two-way ANOVA followed by Bonferroni test.

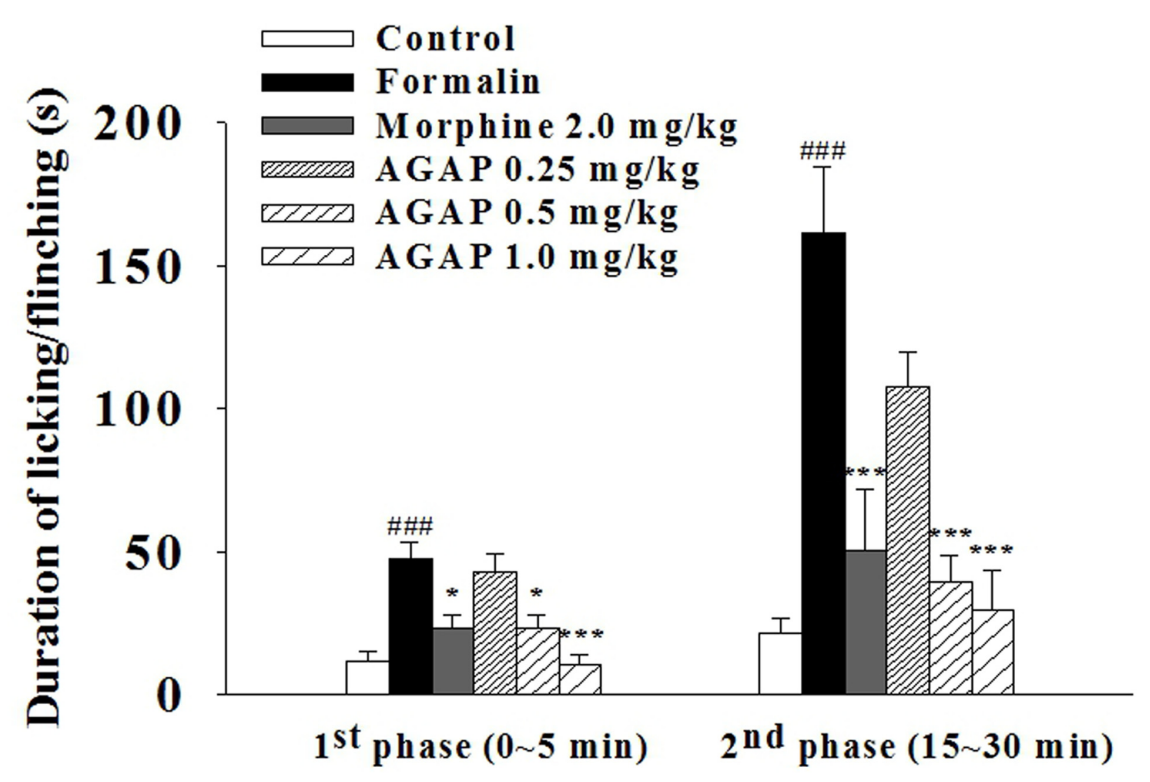

FIGURE 3 | Effect of AGAP against formalin induced licking and flinching in mice. AGAP at concentrations ranging from 0.25 to 1.0 mg/kg was administered intravenously 20 min before formalin injection. Morphine was administered at a dose of $2 \mathrm{mg} / \mathrm{kg}$ i.p. 30 min before formalin injection. The total time spent on licking and flinching of the affected paw was measured in the first (0-5 min) phase and the second (15-30 min) phase after intraplantar injection of formalin. AGAP

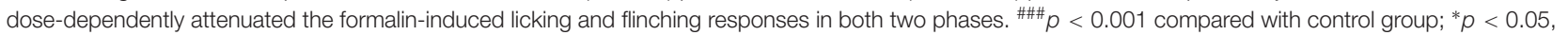
${ }^{* * *} p<0.001$ compared with formalin group. Data are shown as the mean $\pm \operatorname{SEM}(n=12$ per group). $P$ values are from two-way ANOVA followed by Bonferroni test.

\section{Effects of AGAP on Voltage-Dependent Sodium Currents in Rat Amall-Diameter DRG Neurons}

In electrophysiological testing experiment, voltage-dependent calcium and potassium channels were pharmacologically blocked. Sodium currents were maximally activated by a test pulse at -10 and $0 \mathrm{mV}$, and peak amplitude at these potential were $-5262 \pm 928$ and $-4658 \pm 1016 \mathrm{pA}$ in cultured small diameter DRG neurons (Figure 5A, $n=15$ ) and acutely isolated small DRG neurons (Figure 5B, $n=19$ ), respectively. AGAP (1000 nM) inhibited the sodium currents in cultured and acutely isolated small DRG neurons, as shown in Figure 5C $(P<0.05$, $n=19$ and $n=15$, respectively). $5 \mathrm{~min}$ after addition of 

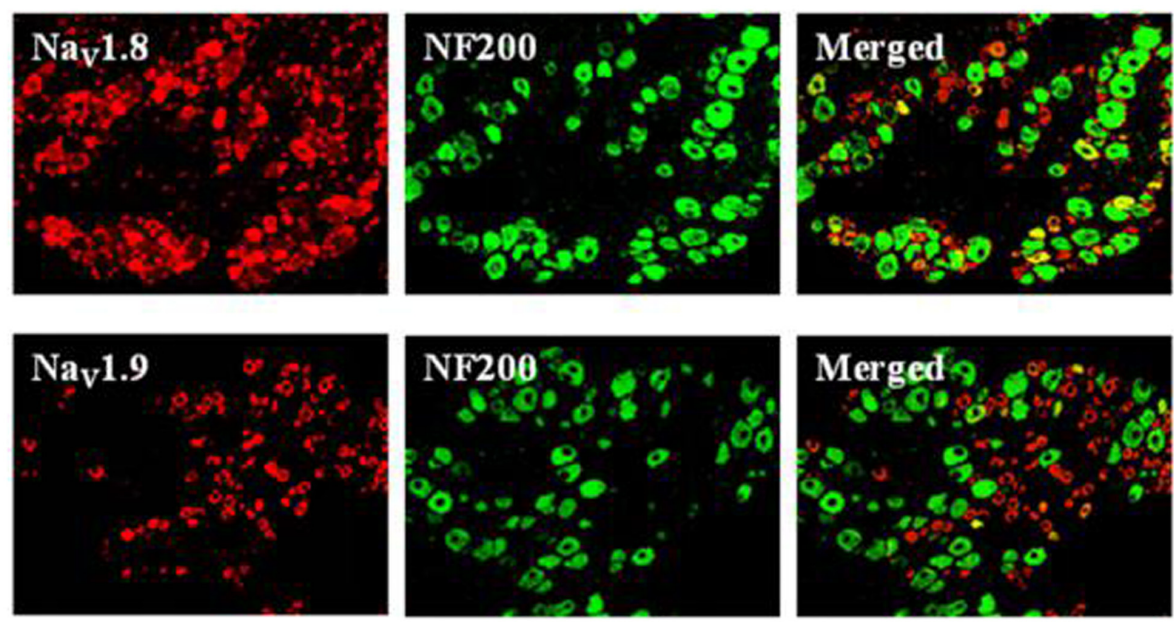

FIGURE 4 | Expression profiles of Nav1.8 and Nav1.9 in DRG neurons (x 200). Double immunofluorescent labeling of $L_{4-6}$ DRG neurons by anti-Nav1.8 (red) and anti-NF200 (green) or anti-Nav1.9 (red) and anti-NF200 (green) antibodies.

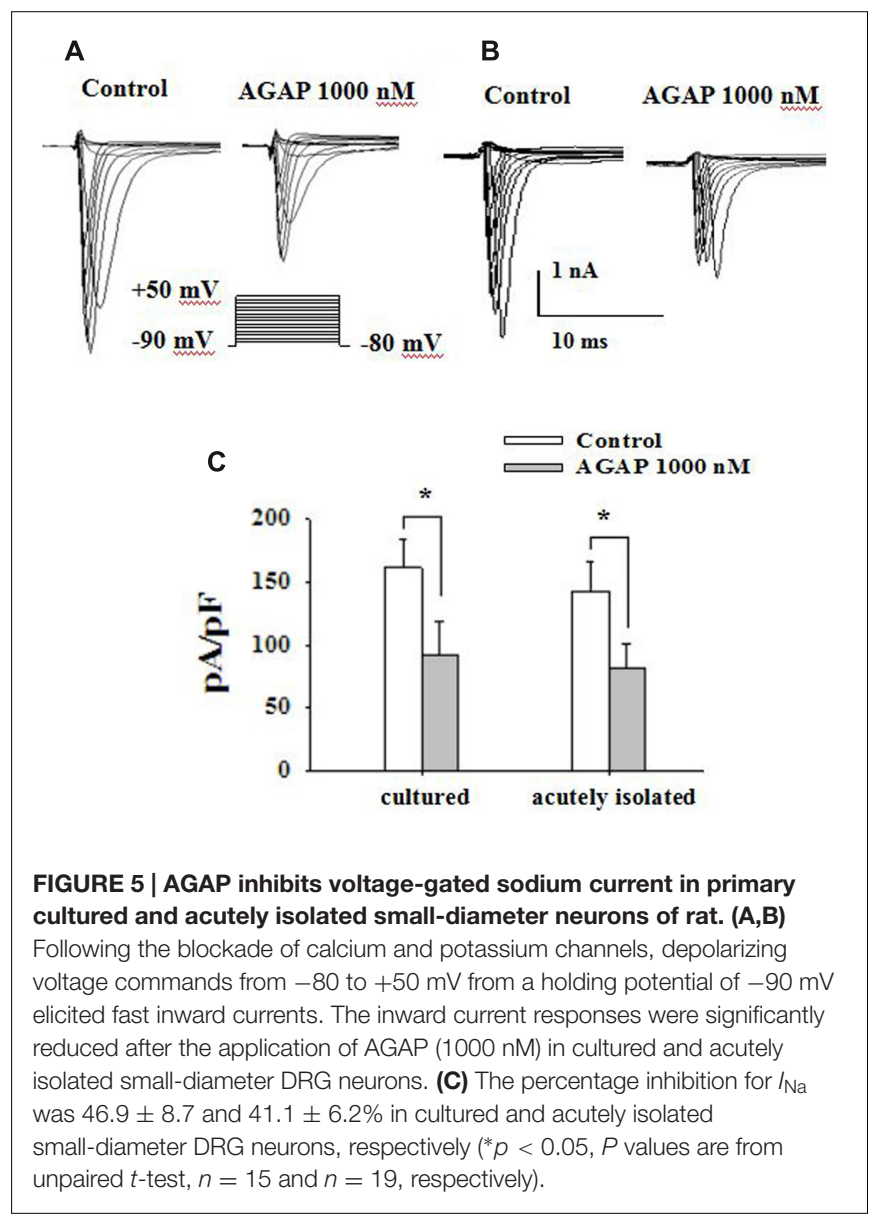

$1000 \mathrm{nM}$ AGAP, the rate of inhibition for $I_{\mathrm{Na}}$ was $46.9 \pm 8.7$ and $41.1 \pm 6.2 \%$ in cultured and acutely isolated small-diameter DRG neurons, respectively. The inhibition effect calculated as the mean reduction of maximum peak amplitude. The results showed that the pharmacological action of AGAP was similar in primary cultured and acutely isolated small DRG neurons. The acutely isolated small diameter DRG neurons were used to accomplish the following experiments.

\section{Effects of AGAP on Current Density-Voltage Relationship and Concentration - Dependent Inhibition of AGAP on Sodium Currents}

Current density-voltage relationships of sodium currents in small-diameter DRG neurons were shown in Figure 6A. AGAP modified the voltage threshold of the activation or the potential at which the inward current reached maximal values. The concentration-responsiveness of AGAP was investigated by measuring current density-voltage relations under different concentrations of AGAP (Figure 6B). AGAP (30-1000 nM) reduced the sodium currents in all the DRG neurons. The process that AGAP reduced the inward sodium currents was dosedependent and the minimal effective concentration was obtained with $30 \mathrm{nM}$ AGAP $(P<0.05, n=8)$. The concentrationresponsiveness in acutely isolated rat small-diameter DRG neurons was shown in Figure 6C.

Then, we examined the effect of AGAP on activation kinetics of the sodium currents. DRG cells were held at $-120 \mathrm{mV}$, then, the membrane was depolarized from -90 to $+60 \mathrm{mV}$ in increments of $10 \mathrm{mV}$. Boltzmann functions constructed from the average values for $V_{1 / 2}$ and $k$ were shown superimposed on the data points with $V_{1 / 2}=-19.1 \pm 0.3 \mathrm{mV}$ in control and $V_{1 / 2}=-25.0 \pm 0.7 \mathrm{mV}$ with $1000 \mathrm{nM}$ AGAP in smalldiameter DRG neurons (Figure 6D, $P<0.05, n=7$ ). AGAP shifted the voltage dependency of activation in rat small-diameter DRG neurons. Slope factors were $3.2 \pm 0.3$ and $2.7 \pm 0.3 \mathrm{mV}$ before and after administration of $1000 \mathrm{nM}$ AGAP. Slope factors were not significantly different (Figure 6D, $P>0.05$, $n=7)$. 

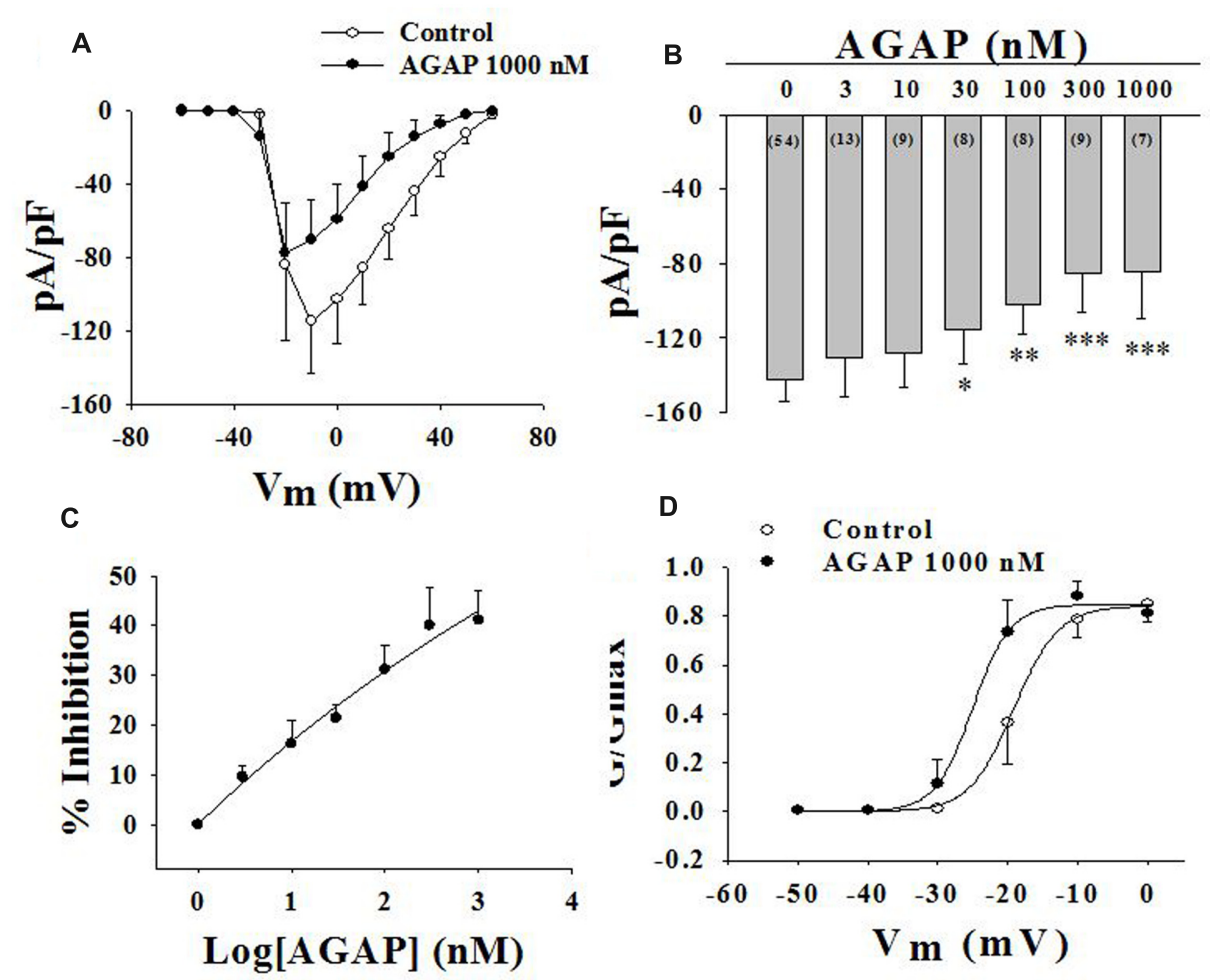

FIGURE 6 | Effect of AGAP on Nav channel currents in small-diameter DRG neurons. (A) Current density-voltage relationship obtained by plotting current density as a function of test potential under control conditions and after application of 1000 nM AGAP. $(n=7)$. (B,C) The graph shows the dose-response relationship of the effect of AGAP in acutely isolated small-diameter DRG neurons ${ }^{*} P<0.05,{ }^{* *} P<0.01,{ }^{* * *} P<0.001, P$ values are from unpaired $t$-test. $n=8-13)$. (D) Effect of AGAP on steady-state activation kinetics of Nav channels. Data points were fitted with the Boltzmann equation. $V_{1 / 2}$ was $-19.1 \pm 0.3 \mathrm{mV}$ under control conditions and $-25.0 \pm 0.7 \mathrm{mV}$ in the presence $1000 \mathrm{nM}$ of AGAP $(P<0.05, P$ values are from unpaired $t$-test. $n=7)$; slope factors were $3.2 \pm 0.3$ and $2.7 \pm 0.3 \mathrm{mV}$, respectively.

\section{Effects of AGAP on TTX-R Sodium Currents in Rat Small-Diameter DRG Neurons}

The TTX-S sodium currents of the rat small-diameter DRG neurons could be abolished by $1 \mu \mathrm{M}$ TTX, indicating that the sodium channels expressing in small-diameter DRG neurons have TTX-S and TTX-R sodium channels (Figure 7A). Our current density-voltage relationship of TTX-R sodium currents in DRG neurons was shown in Figure 7B. These inward TTX-R sodium currents were maximally activated by a test pulse at -10 and $0 \mathrm{mV}(n=6)$.

In a first series of experiments, calcium, potassium and TTX-S sodium currents were pharmacologically blocked by extracellular application of 4-AP, TEA, $\mathrm{La}^{3+}$ and TTX as well as by the addition of $\mathrm{Cs}^{+}$in the recording electrode. Effects of AGAP on TTX-R sodium currents were investigated in DRG neurons after complete inhibition of TTX-S $I_{\mathrm{Na}}$ currents using $1.0 \mu \mathrm{M}$ TTX. The results showed that AGAP $1000 \mathrm{nM}$ reduced TTX-R $I_{\mathrm{Na}}$ peak amplitude by $42.8 \%$ (Figures 7C,D, $P<0.01, n=9$ ). The peak amplitudes were $-1070.1 \pm 407.9$ and $-636.2 \pm 253.5 \mathrm{nA}$ before and after the application of $1000 \mathrm{nM}$ AGAP.

Effects of AGAP on $\mathrm{Na}_{V} 1.8$ currents were investigated in acutely isolated rat DRG neurons lacking detectable $\mathrm{Na}_{V}$ 1.9.
Figure 7C shows representative $\mathrm{Na}_{\mathrm{V}} 1.8$ current traces. Currents were elicited by steps to membrance potential between -90 and $+60 \mathrm{mV}$ from a holding potential of $-120 \mathrm{mV}$, at which most channels are in the resting-state. AGAP had obvious inhibitory effects on $\mathrm{Na}_{V} 1.8$ current amplitudes. $1000 \mathrm{nM}$ of AGAP reduced $\mathrm{Na}_{V} 1.8$ current amplitudes by 59.4\% (Figures 7E,F, $P<0.01$, $n=5)$. Representative $\mathrm{Na}_{\mathrm{V}} 1.9$ current traces are shown in Figure 7G in control condition and in the presence of $1000 \mathrm{nM}$ AGAP. Currents were elicited by depolarizing steps to $-35 \mathrm{mV}$ from a Vh of $-100 \mathrm{mV}$. AGAP (1000 nM) inhibited $\mathrm{Na}_{\mathrm{V}} 1.9$ current amplitudes at 33.7\% (Figure $7 \mathbf{H}, P<0.05, n=9$ ). Mean value of Nav1.8 and Nav1.9 sodium currents reversal potential are +55 and $+63 \mathrm{mV}$, respectively.

\section{Effects of AGAP on Steady-State Activation and Inactivation Kinetics of Nav1.8 Currents}

Voltage-dependent steady-state activation and inactivation properties of sodium channels contribute to membrane excitability. Therefore, some kinetic properties of the $\mathrm{Na}_{\mathrm{V}} 1.8$ and $\mathrm{Na}_{V} 1.9$ channels were investigated in small-diameter DRG neurons. $\mathrm{Na}_{\mathrm{V}} 1.8$ currents were evoked to $-50 \mathrm{mV}$ over the course of $500 \mathrm{~ms}$, followed by the application of voltage 
A

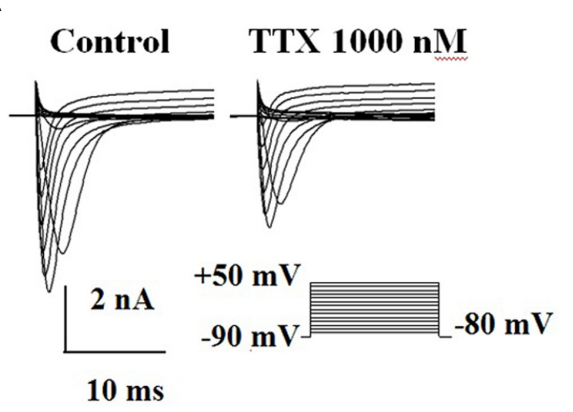

c

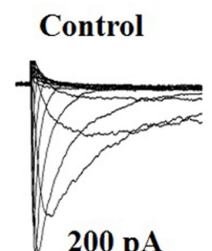

TTX-R

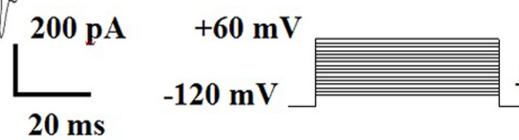

E

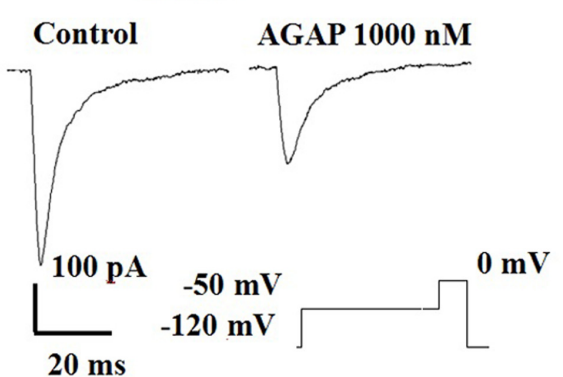

Nav1.9

G

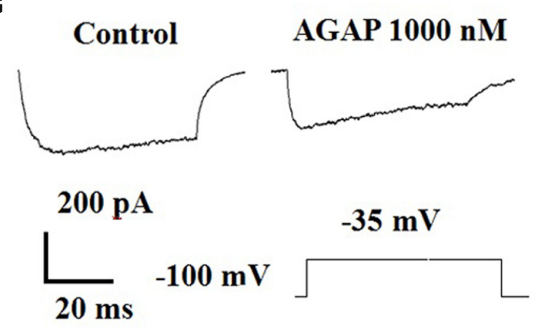

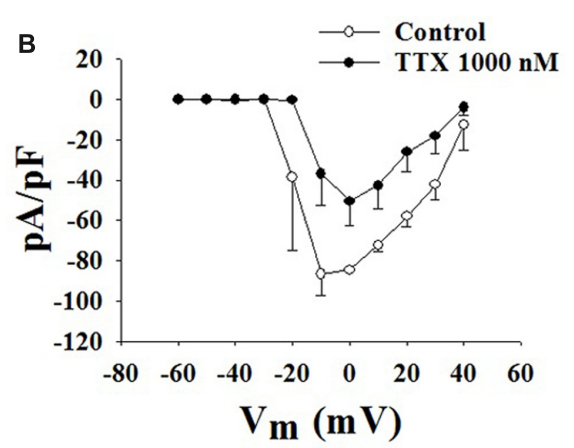

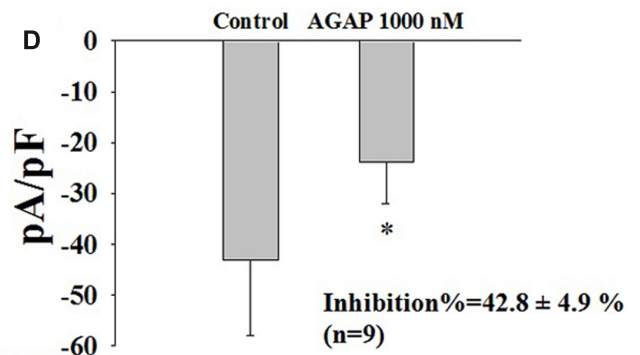

$-90 \mathrm{mV}$

$(\mathrm{n}=9)$
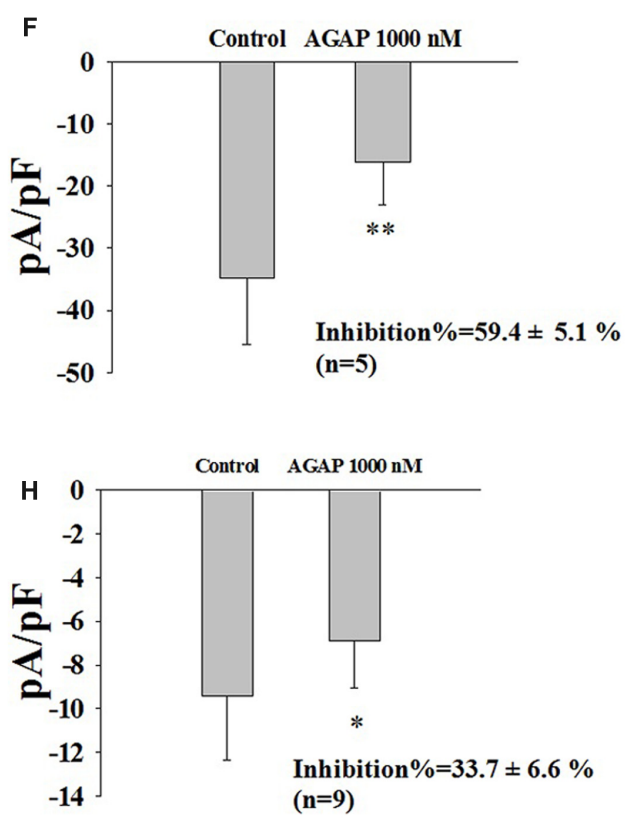

FIGURE 7 | Effect of AGAP on the TTX-R sodium currents in small-diameter DRG neurons. (A) Representative traces showing the depression of $1000 \mathrm{nM}$ TTX on Nav channel currents in rat small diameter DRG neuron. (B) Current density-voltage relationship obtained by plotting current density as a function of test potential under control conditions and after application of $1000 \mathrm{nM} \operatorname{TXX}(n=6)$. (C) Representative traces showing the depression of AGAP on TTX-R currents in a neuron. (D) $1000 \mathrm{nM}$ AGAP inhibited TTX-R currents by $42.8 \%(P<0.05, P$ values are from unpaired $t$-test, $n=9)$. (E) Representative traces showing the depression of AGAP on Nav1.8 currents in a neuron. (F) At a concentration of $1000 \mathrm{nM}$, AGAP potently inhibited Nav1.8, decreasing current amplitude by $59.4 \%$ $(P<0.01, P$ values are from unpaired $t$-test. $n=5)$. (G) Representative traces showing the depression of AGAP on Nav1.9 currents in a neuron. (H) $1000 \mathrm{nM}$ AGAP reduced Nav1.9 currents by $33.7 \%(P<0.05, P$ values are from unpaired $t$-test. $n=9)$.

steps ranging from -50 to $+50 \mathrm{mV}$ in increments of $10 \mathrm{mV}$ (Figure 8A). The normalized peak conductance was plotted against voltage and fitted with the Boltzmann equation. AGAP shifted negatively the $V_{1 / 2}$ of activation by $4.6 \mathrm{mV}$ from
$-13.0 \pm 0.2 \mathrm{mV}$ in control conditions to $-17.6 \pm 0.4 \mathrm{mV}$ (Figure 8B, $P<0.05, n=5$ ). Slope factors were $2.8 \pm 0.1$ and $4.2 \pm 0.3 \mathrm{mV}$ before and after application of $1000 \mathrm{nM}$ AGAP (Figure 8B, $P<0.05, n=5$ ). 

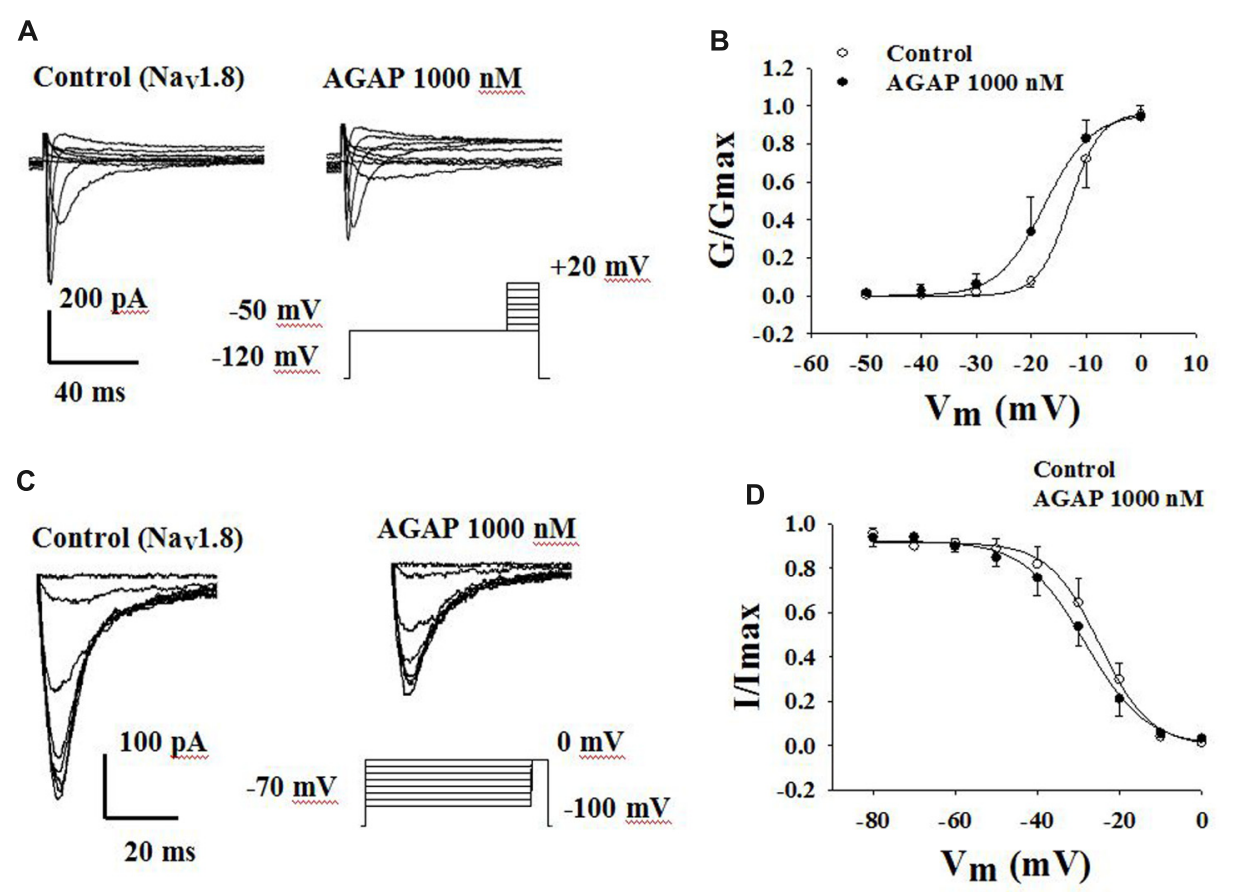

FIGURE 8 | Effect of AGAP on the dynamic function of $\mathbf{N a}_{\mathbf{v}} \mathbf{1 . 8}$ channels. (A,B) AGAP shifts the conductance-voltage relationship to more negative potentials. (A) Representative steady-state activation of Nav1.8 under the control conditions and in the presence of 1000 nM AGAP. (B) Normalized activation kinetics determined before and after the application of AGAP. $V_{1 / 2}$ was $-13.0 \pm 0.2 \mathrm{mV}$ in control conditions and $-17.6 \pm 0.4 \mathrm{mV}$ in the presence of $1000 \mathrm{nM} \mathrm{AGAP}$ $(P<0.05, n=5)$. Slope factors were $2.8 \pm 0.1$ and $4.2 \pm 0.3 \mathrm{mV}$, respectively $(P<0.05, n=5)$. $P$ values are from unpaired $t$-test. (C,D) AGAP had no effect on the voltage-dependence of steady-state inactivation. (C) Representative steady-state inactivation of Nav1.8 under the control conditions and in the presence of $1000 \mathrm{nM}$ AGAP. (D) Normalized peak currents were plotted against membrane potential and Boltzmann equation was used to fit data. $V_{1 / 2}$ was $-25.0 \pm 0.3 \mathrm{mV}$ in control conditions and $-25.4 \pm 0.6 \mathrm{mV}$ in the presence of $1000 \mathrm{nM}$ AGAP. Slope factors were $-5.5 \pm 0.3$ and $-6.0 \pm 0.5 \mathrm{mV}$, respectively $(P>0.05, P$ values are from unpaired t-test. $n=5)$.

To study the properties of steady-state inactivation of $\mathrm{Na}_{\mathrm{V}} 1.8$ channels, a series of prepulses from -70 to $0 \mathrm{mV}$ were followed by a testing pulse of $0 \mathrm{mV}$. AGAP (1000 nM) slightly shifted the inactivation curves of Nav1.8 but there were no significant differences (Figure 8C). $V_{1 / 2}$ values were $-24.9 \pm 0.6$ and $-28.4 \pm 0.6 \mathrm{mV}$ in the absence or presence of AGAP. Slope factors were $-6.1 \pm 0.5$ and $-7.4 \pm 0.5 \mathrm{mV}$, respectively. Steadystate inactivations and slope factors were not statistically different in the absence or presence of AGAP (Figure 8D, $P>0.05$, $n=5)$.

\section{Effects of AGAP on Steady-State Activation and Inactivation Kinetics of Nav1.9 Currents}

Another TTX-R sodium channel expressed in DRG neurons is $\mathrm{Na}_{V}$ 1.9. $\mathrm{Na}_{V} 1.9$ generates a low-threshold sodium current with slow rates of activation and inactivation, giving rise to a persistent current component. Fluoride-containing patch pipette solution was used to record $\mathrm{Na}_{\mathrm{V}} 1.9$ currents. Activation properties were studied by applying voltage steps from -80 to $-35 \mathrm{mV}$ from a holding potential of $-100 \mathrm{mV}$ (Figure 9A). AGAP (1000 nM) had no significant effects on the voltage-dependence of the activation curves. $V_{1 / 2}$ for activation was $-38.4 \pm 1.5 \mathrm{mV}$ in control conditions and $-38.2 \pm 3.7 \mathrm{mV}$ in the presence of
$1000 \mathrm{nM}$ AGAP. Slope factors were $6.1 \pm 0.5$ and $7.8 \pm 1.1 \mathrm{mV}$, respectively (Figure 9B, $P>0.05, n=7$ ).

To study the properties of steady-state inactivation of $\mathrm{Na}_{\mathrm{V}} 1.9$ channels, a series of prepulses from -120 to $0 \mathrm{mV}$ were followed by a testing pulse of $-50 \mathrm{mV}$ (Figure 9C). AGAP (1000 nM) had no significant effects on Nav1.9 channel inactivation (Figure 9D). The values of the parameters of $V_{1 / 2}$ and $k$ were $-67.9 \pm 2.2$ and $-11.0 \pm 1.8 \mathrm{mV}$ under control conditions and $-69.6 \pm 2.5$ and $-12.5 \pm 2.0 \mathrm{mV}$ in the presence of $1000 \mathrm{nM}$ AGAP, respectively (Figure 9D, $P>0.05$, $n=6)$.

\section{DISCUSSION}

Recent evidences that sodium channel activities and expressions altered in peripheral neurons can contribute to the pathophysiology of peripheral neuropathy (Lai et al., 2002; Amir et al., 2006; Dib-Hajj et al., 2010). Scorpion venom has been proved to be a rich source of ion channel regulators. Here, we examined the effect of AGAP, a long-chain scorpion peptides, to anti-nociception by studying behavioral phenotypes of mice. Subsequently, the effect of AGAP on VGSCs was detected in rat small-diameter DRG neurons by whole-cell patch clamp technique. 
A

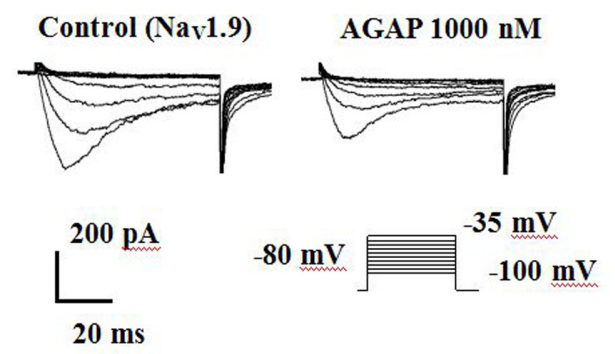

\section{Control (Nav1.9)}

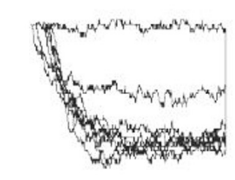

$\bigsqcup_{20}^{30} \mathrm{pA}$

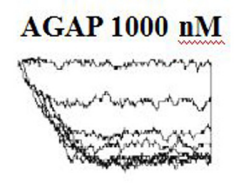

$-50 \mathrm{mV}$
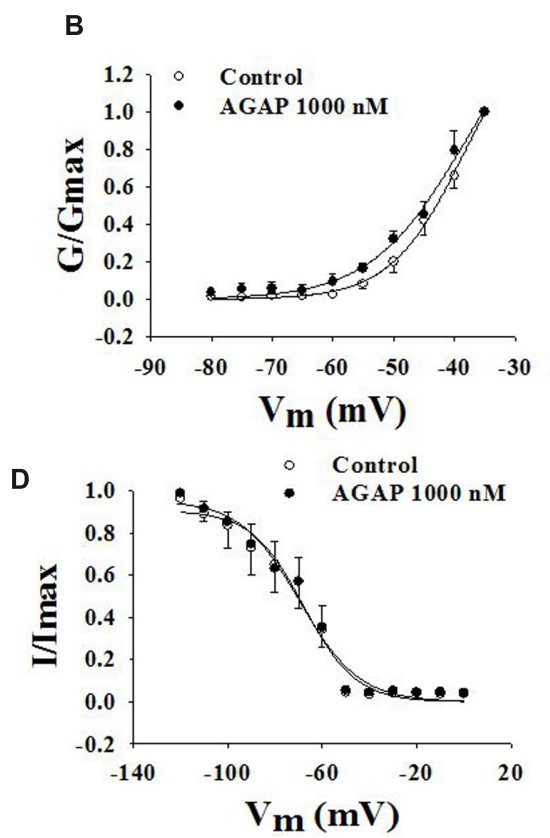

FIGURE 9 | Effect of AGAP on the dynamic function of Nav1.9 channels. 1000 nM AGAP did not significantly affect the voltage-dependence of channel activation or steady-state inactivation. (A,B) Effect of AGAP on steady-state activation kinetics of Nav 1.9 currents. $V_{1 / 2}$ was $-38.4 \pm 1.5 \mathrm{mV}$ in control conditions and $-38.2 \pm 3.7 \mathrm{mV}$ in the presence of $1000 \mathrm{nM}$ AGAP. Slope factors were $6.1 \pm 0.5$ and $7.8 \pm 1.1 \mathrm{mV}$, respectively $(n=7)$. (C,D) Steady-state inactivated of Nav1.9 in the absence and presence of AGAP. $V_{1 / 2}$ for inactivation was $-67.9 \pm 2.2 \mathrm{mV}$ in control conditions and $-69.6 \pm 2.5 \mathrm{mV}$ in the presence of $1000 \mathrm{nM}$ AGAP. Slope factors were $-11.0 \pm 1.8$ and $-12.5 \pm 2.0 \mathrm{mV}$, respectively $(P>0.05, P$ values are from unpaired $t$-test. $n=6)$.

The results showed that AGAP significantly inhibited the response of writhing in a dose-dependent manner on acetic-acidinduced writhing. We further investigated the antinociceptive role of AGAP in an acute inflammatory pain condition induced by intraplantar injection of formalin. Our results confirmed that AGAP had a significant analgesic activity in both the first and second phases. Besides, AGAP also showed a significant increase in latency to the thermal stimuli in hot plate test, suggests a better antinociceptive activity of AGAP.

Some small peptide inhibitors of N-type channel have shown effect in the treatment of pain. Such as the $\omega$-conotoxin MVIIA has been isolated from venom of Conus magus has been used to treat intractable pain as an analgesic drug (Staats et al., 2004; Stix, 2005). The possible reason is that these inhibitors block the synaptic transmission of signal pathways of pain to the central nervous system (Feng et al., 2001; Yarotskyy and Elmslie, 2009). Most of the long-chain scorpion peptides are the modulators of sodium and calcium channels (Possani et al., 2000; Li et al., 2004). The previous study has shown that AGAP potently inhibited voltage-gated calcium channels in the small diameter DRG neurons (Liu et al., 2014). We have demonstrated that AGAP decreases the HVA calcium channels, especially N-type calcium currents, while $\mathrm{N}$-type calcium channels are expressed in presynaptic and may have more influence on EPSC/EPSP than other calcium type (Tsuzuki et al., 2004). Voltage-gated L-type calcium channels help to maintain longer-lasting depolarizations to reduce firing threshold and regulate repetitive firing as well as shaping regenerative action potentials. Our results strongly suggest that the modulation of VGCCs is a possible mechanism for reduction of neuronal excitability.

These results suggest that antinociceptive effect of AGAP may be ascribed to its specific modulation of voltage-gated ion channels of sensory neurons. Comparing the important role of voltage-gated calcium channels, VGSCs are present in excitable membranes and play a fundamental role in action potentials generation (Payandeh et al., 2011). VGSCs are the important targets for analgesic drugs (Sleeper et al., 2000; Maingret et al., 2008). Next, to determine the effect whether AGAP modulates sodium channels underlying the generation of pain. We found AGAP decreased the sodium currents in a concentration-dependent manner. To our studies, this is the first experimental evidence demonstrating that AGAP is an ion channel regulator with many different actions on a variety of neuronal ion channels including HVA, LVA calcium channels and TTX-R sodium channels.

Nav1.8 and Nav1.9 contain a structural common motif of TTX-R sodium channel subtype that both of them are remarkably expressed in peripheral sensory neurons (Dib-Hajj et al., 2010; Yu et al., 2011), and are thought to play an important role in ectopic discharge in neuronal bodies and axons following peripheral nerve injury (Akopian et al., 1996; Dib-Hajj et al., 1998; Kral et al., 1998; Berta et al., 2008); these properties have identified them as potential molecular targets for analgesic drugs. Both TTX-R subtypes, Nav1.8 and Nav1.9, have been 
implicated in nociception, including neuronal pain signaling triggered by inflammation (Lai et al., 2002, 2004), and the Nav1.8 is essential for neuropathic pain at low temperatures (Zimmermann et al., 2007). The result confirms that AGAP might attenuate pain by blocking TTX-R channels in smalldiameter DRG neurons. Our further results showed that $1000 \mathrm{nM}$ AGAP reduced the Nav1.8 and Nav1.9 currents, the inhibitory percentage of Nav1.8 and Nav1.9 currents were $59.4 \pm 5.1$ and $33.7 \pm 6.6 \%$, respectively. The results suggested that the effect of AGAP on Nav1.8 channels was stronger than that of Nav1.9 channels.

The voltage-gated Nav1.8 channel has been demonstrated having a significantly higher inactivation threshold, slower inactivation kinetics, and a faster recovery from inactivation comparing with TTX-S Na+ channels (Cummins and Waxman, 1997), this suggests that Nav1.8 channel is a major contributor to the action potential upstroke in C-type small DRG neurons (Renganathan et al., 2001). The Nav1.8 expression has been reported to increase in the setting of persistent inflammatory pain (Gaida et al., 2005; Villarreal et al., 2005). Some studies suggest that Nav1.8 mutations contribute to pain in some peripheral neuropathies (Faber et al., 2012). Our results showed that AGAP suppresses Nav1.8 currents, suggesting the upstroke of the action potential is blocked by AGAP in sensitive neurons. We predicted that AGAP can reduce Nav1.8 currents, decrease membrane excitability and block AP propagation in nociceptive sensory neurons as well.

AGAP significantly shifted the steady-state activation curves of Nav1.8 currents to more negative potentials, and the inactivation curves of Nav1.8 currents were also shifted to negative potentials. The shift of steady-state activation may speed up the activation process of Nav1.8 channel. At the same time AGAP may also expedite the inactivation process, this is, the time to entry into activation is shortened.

Nav1.8 is important in the development and/or maintenance of nerve injury-induced pain, several Nav1.8-selective inhibitors have been reported to be analgesic in several neuropathic (Jarvis et al., 2007), and it has also been suggested that Nav1.8 might be a potential target of AGAP in inflammatory and neuropathic antinociceptive mechanism.

The Nav1.9 channel is preferentially expressed in nociceptive DRGs and trigeminal nerve neurons (Amaya et al., 2000; Eriksson et al., 2005; Fang et al., 2006), and is known to contribute to the persistent thermosensitive and spontaneous pain by peripheral administration of inflammatory mediators (Crill, 1996; Coste et al., 2004; Priest et al., 2005). The present results showed that AGAP efficiently inhibited Nav1.9 channels in small-diameter DRG neurons in a concentration-dependent manner. The decrease of Nav1.9 currents was associated with subthreshold regenerative depolarization, active hyperpolarizing responses, oscillatory bursting discharges, plateau potentials and bistable membranes behaviors (Maingret et al., 2008). Our results suggested that following the inhibition of AGAP in Nav1.9 channels, the currents reduction of Nav1.9 and the subsequent loss of this depolarizing influence would cause a hyperpolarizing shift in resting potential, elevating the threshold for initiating action potentials.
Nav1.9 channels play a major role in mediating inflammatory rather than neuropathic pain, and contribute to the hyperexcitability of nociceptors observed during inflammatory pain (Priest et al., 2005; Amaya et al., 2006; Ostman et al., 2008). Cummins and Waxman (1997) suggested that, following axotomy, downregulation of Nav1.9 and the subsequent loss of this depolarizing influence would cause a hyperpolarizing shift in resting potential and remove resting inactivation on TTX-S $\mathrm{Na}^{+}$channels, thereby producing hyperexcitability. A link between the Nav1.9-associated persistent current and the pain sensation was demonstrated in neurons from Nav1.9 knockout mice that lack persistent $\mathrm{Na}^{+}$current and have greatly reduced inflammatory hyperalgesia (Priest et al., 2005; Amaya et al., 2006). AGAP reduced the Nav1.9 current, but activation or steady-state inactivation of Nav1.9 was not significantly changed in small-diameter DRG neurons. The results suggest that the AGAP may decrease the effect of Nav1.9 about depolarization of the resting membrane potential, lowering the threshold level for initiating subsequent action potentials (Cummins et al., 1999; Herzog et al., 2001; Baker et al., 2003). AGAP might attenuate inflammatory pain by blocking Nav1.9 sodium channels in nociceptors.

Some researches indicted that TTX-R sodium channels might not be related to the conduction of potential, but have an import role in the action potential generation. The currents reduced by AGAP of Nav1.8 and Nav1.9 channels may also reduce the generation of action potentials. Neurotoxins alter ion channel functions by binding to different sites (Ekberg et al., 2008). Scorpion toxins were individed into $\alpha$ - and $\beta$-scorpion toxins. The $\alpha$-scorpion toxins, which bind to site 3 on VGSCs, slow inactivation processes, and the $\beta$-scorpion toxins, which binds to site 4 on VGSC, enhance the activation process. Scorpion depressant $\beta$-toxins are considered as analgesic peptides (Chen et al., 2006). According to electrophysiological characteristics of AGAP compared to those of other scorpion toxins, AGAP can be classified as a $\beta$-neurotoxin.

In summary, our results have shown that AGAP had a significant anti-nociceptive activity in an animal model of pain. AGAP as potential analgesics is still in the preclinical stage. Although AGAP could modulate the function of calcium channels and TTX-R sodium channels in DRG neurons, AGAPinduced modulation on other ion channels still need to be further investigated. But according to our results, AGAP modulated currents of calcium channels and TTX-R sodium currents in small-diameter DRG neurons, which probably partly contributes to the mechanism of the decreased neuron excitability, blocking neuronal signaling and inducing analgesia.

\section{AUTHOR CONTRIBUTIONS}

C-FW is the leader of our lab and project. C-LL selected, designed, and wrote the paper. Our work was mainly carried out by X-FL and G-XL and also partly designed by them two. Molecular biological parts was carried out by J-ZC and M-qB. Our peptide, AGAP, was provided from J-HZ and biological support was from Associate YC. 


\section{ACKNOWLEDGMENTS}

This study was supported by the National Natural Science Foundation of China (No: 81073081, 81102365), the National

\section{REFERENCES}

Akopian, A. N., Sivilotti, L., and Wood, J. N. (1996). A tetrodotoxin-resistant voltage-gated sodium channel expressed by sensory neurons. Nature 379, $257-$ 262. doi: $10.1038 / 379257 \mathrm{a} 0$

Amaya, F., Decosterd, I., Samad, T. A., Plumpton, C., Tate, S., Mannion, R. J., et al. (2000). Diversity of expression of the sensory neuron-specific TTX-resistant voltage-gated sodium ion channels SNS and SNS2. Mol. Cell. Neurosci. 15, 331-342. doi: 10.1006/mcne.1999.0828

Amaya, F., Wang, H., Costigan, M., Allchorne, A. J., Hatcher, J. P., Egerton, J., et al. (2006). The voltage-gated sodium channel $\mathrm{Na}(\mathrm{v}) 1.9$ is an effector of peripheral inflammatory pain hypersensitivity. J. Neurosci. 26, 12852-12860. doi: 10.1523/JNEUROSCI.4015-06.2006

Amir, R., Argoff, C. E., Bennett, G. J., Cummins, T. R., Durieux, M. E., Gerner, P., et al. (2006). The role of sodium channels in chronic inflammatory and neuropathic pain. J. Pain 7(5 Suppl. 3), S1-S29. doi: 10.1016/j.jpain.2006.01.444

Araújo, I. W., Rodrigues, J. A., Quindere, A. L., Silva, J., Maciel, G., Rebeiro, K. A., et al. (2016). Analgesic and anti-inflammatory actions on bradykinin route of a polysulfated fraction from alga Ulva lactuca. Int. J. Biol. Macromol. 92, 820-830. doi: 10.1016/j.ijbiomac.2016.07.094

Baker, M. D., Chandra, S. Y., Ding, Y., Waxman, S. G., and Wood, J. N. (2003). GTP-induced tetrodotoxin-resistant $\mathrm{Na}+$ current regulates excitability in mouse and rat small diameter sensory neurones. J. Physiol. 548(Pt 2), 373-382. doi: 10.1113/jphysiol.2003.039131

Berta, T., Poirot, O., Pertin, M., Ji, R. R., Kellenberger, S., and Decosterd, I. (2008). Transcriptional and functional profiles of voltage-gated $\mathrm{Na}(+)$ channels in injured and non-injured DRG neurons in the SNI model of neuropathic pain. Mol. Cell. Neurosci. 37, 196-208. doi: 10.1016/j.mcn.2007.09.007

Caffrey, J. M., Eng, D. L., Black, J. A., Waxman, S. G., and Kocsis, J. D. (1992). Three types of sodium channels in adult rat dorsal root ganglion neurons. Brain Res. 592, 283-297. doi: 10.1016/0006-8993(92)91687-A

Casarrubea, M., Sorbera, F., Santangelo, A., and Crescimanno, G. (2012). The effects of diazepam on the behaviorar structure of rat's response to pain in the hot plate test: anxiolysis vs. Pain modulation. Neuropharmacology 63, 310-321. doi: 10.1016/j.neuropharm.2012.03.026

Chen, J., Feng, X. H., Shi, J., Tan, Z. Y., Bai, Z. T., Liu, T., et al. (2006). The antinociceptive effect of BmK AS, a scorpion active polypeptide, and the possible mechanism on specifically modulating voltage-gated $\mathrm{Na}+$ currents in primary afferent neurons. Peptides 27, 2182-2192. doi: 10.1016/j.peptides.2006.03.026

Coste, B., Osorio, N., Padilla, F., Crest, M., and Delmas, P. (2004). Gating and modulation of presumptive NaV1.9 channels in enteric and spinal sensory neurons. Mol. Cell. Neurosci. 26, 123-134. doi: 10.1016/j.mcn.2004.01.015

Crill, W. E. (1996). Persistent sodium current in mammalian central neurons. Annu. Rev. Physiol. 58, 349-362. doi: 10.1146/annurev.ph.58.030196.002025

Cummins, T. R., Dib-Hajj, S. D., Black, J. A., Akopian, A. N., Wood, J. N., and Waxman, S. G. (1999). A novel persistent tetrodotoxin-resistant sodium current in SNS-null, and wild-type small primary sensory neurons. J. Neurosci. 19:RC43.

Cummins, T. R., and Waxman, S. G. (1997). Downregulation of tetrodotoxinresistant sodium currents and upregulation of a rapidly repriming tetrodotoxinsensitive sodium current in small spinal sensory neurons after nerve injury. J. Neurosci. 17, 3503-3514.

Dib-Hajj, S. D., Cummins, T. R., Black, J. A., and Waxman, S. G. (2010). Sodium channels in normal and pathological pain. Annu. Rev. Neuosci. 33, 325-347. doi: 10.1146/annurev-neuro-060909-153234

Dib-Hajj, S. D., Tyrrell, L., Black, J. A., and Waxman, S. G. (1998). NaN, a novel voltage-gated $\mathrm{Na}$ channel, is expressed preferentially in peripheral sensory neurons and down-regulated after axotomy. Proc. Natl. Acad. Sci. U.S.A. 95, 8963-8968. doi: 10.1073/pnas.95.15.8963

Djouhri, L., Fang, X., Koutsikou, S., and Lawson, S. N. (2012). Partial nerve injury induces electrophysiological changes in conducting (uninjured) nociceptive and nonnociceptive DRG neurons: possible relationships to aspects of
Natural Science Foundation of Liaoning Province (No: 2015020744), Shenyang municipal science and technology plan projects (No: F-16-205-1-32) and the project of Education department of Liaoning Province (No: 20161016L21).

peripheral neuropathic pain and paresthesias. Pain 153, 1824-1836. doi: 10 1016/j.pain.2012.04.019

Ebersberger, A., Natura, G., Eitner, A., Halbhuber, K. J., Rost, R., and Schaible, H. G. (2011). Effects of prostaglandin D2 on tetrodotoxin-resistant $\mathrm{Na}+$ currents in DRG neurons of adult rat. Pain 152, 1114-1126. doi: 10.1016/j.pain.2011.01.033

Ekberg, J., Craik, D. J., and Adams, D. J. (2008). Conotoxin modulation of voltagegated sodium channels. Int. J. Biochem. Cell Biol. 40, 2363-2368. doi: 10.1016/j. biocel.2007.08.017

Eriksson, J., Jablonski, A., Persson, A. K., Hao, J. X., Kouya, P. F., WiesenfeldHallin, Z., et al. (2005). Behavioral changes and trigeminal ganglion sodium channel regulation in an orofacial neuropathic pain model. Pain 119, 82-94. doi: 10.1016/j.pain.2005.09.019

Faber, C. G., Lauria, G., Merkies, I. S., Cheng, X., Han, C., Ahn, H. S., et al. (2012). Gain-of-function Nav1.8 mutations in painful neuropathy. Proc. Natl. Acad. Sci. U.S.A. 109, 19444-19449. doi: 10.1073/pnas.1216080109

Fang, X., Djouhri, L., McMullan, S., Berry, C., Waxman, S. G., Okuse, K., et al. (2006). Intense isolectin-B4 binding in rat dorsal root ganglion neurons distinguishes C-fiber nociceptors with broad action potentials and high Nav1.9 expression. J. Neurosci. 26, 7281-7292. doi: 10.1523/JNEUROSCI.1072-06.2006

Feng, Z. P., Hamid, J., Doering, C., Bosey, G. M., Snutch, T. P., and Zamponi, G. W. (2001). Residue Gly1326 of the N-type calcium channel alpha $1 \beta$ subunit controls reversibility of omega-contoxin GVIA and MVIIA block. J. Biol. Chem. 276, 15728-15735. doi: 10.1074/jbc.M100406200

Gaida, W., Klinder, K., Arndt, K., and Weiser, T. (2005). Ambroxol, a Nav1.8-preferring $\mathrm{Na}(+)$ channel blocker, effectively suppresses pain symptoms in animal models of chronic, neuropathic and inflammatory pain. Neuropharmacology 49, 1220-1227. doi: 10.1016/j.neuropharm.2005. 08.004

Herzog, R. I., Cummins, T. R., and Waxman, S. G. (2001). Persistent TTXresistant $\mathrm{Na}+$ current affects resting potential and response to depolarization in simulated spinal sensory neurons. J. Neurophysiol. 86, 1351-1364.

Jarvis, M. F., Honore, P., Shieh, C. C., Chapman, M., Joshi, S., Zhang, X. F., et al. (2007). A-803467, a potent and selective Nav1.8 sodium channel blocker, attenuates neuropathic and inflammatory pain in the rat. Proc. Natl. Acad. Sci. U.S.A. 104, 8520-8525. doi: 10.1073/pnas.0611364104

Jeftinija, S. (1994). The role of tetrodotoxin-resistant sodium channels of small primary afferent fibers. Brain Res. 639, 125-134. doi: 10.1016/00068993(94)91772-8

Kral, M. G., Xiong, Z., and Study, R. E. (1998). Alteration of Na+ currents in dorsal root ganglion neurons from rats with a painful neuropathy. Pain 81, 15-24. doi: 10.1016/S0304-3959(98)00264-4

Lai, J., Gold, M. S., Kim, C. S., Bian, D., Ossipov, M. H., Hunter, J. C., et al. (2002). Inhibition of neuropathic pain by decreased expression of the tetrodotoxinresistant sodium channel. NaV1.8. Pain 95, 143-152. doi: 10.1016/S03043959(01)00391-8

Lai, J., Porreca, F., Hunter, J. C., and Gold, M. S. (2004). Voltage-gated sodium channels and hyperalgesia. Annu. Rev. Pharmacol. 44, 371-397. doi: 10.1146/an nurev.pharmtox.44.101802.121627

Li, C. L., Yang, B. F., Zhang, J. H., Jiao, J. D., Li, B. X., and Wu, C. F. (2010). Effect of ANEPIII, a novel recombinant neurotoxic polypeptide, on sodium channels in primary cultured rat hippocampal and cortical neurons. Regul. Pept. 164, 105-112. doi: 10.1016/j.regpep.2010.05.010

Li, G. X., Liu, X. F., Du, J. N., Chen, J. Z., She, F. L., Wu, C. F., et al. (2015). Negative shift of Nav1.8 current inactivation curve in injured neurons, not compensatory redistribute in contralateral uninjured neurons, enables neuropathic pain under the state of chronic constriction injury. Mol. Med. Rep. 12, 3583-3590.

Li, M. H., Zhang, N. X., Chen, X. Q., Wu, G., Wu, H., and Hu, G. Y. (2004). Purification and pharmacological characterization of BmKK2 (alpha-KTx 14.2), a novel potassium channel-blocking peptide, from the venom of Asian scorpion Buthus martensi Karsch. Toxicon 43, 895-900. doi: 10.1016/j.toxicon.2003.11. 028 
Liu, X., Li, C., Chen, J., Du, J., Zhang, J., Li, G., et al. (2014). AGAP, a new recombinant neurotoxic polypeptide, targets the voltage-gated calcium channels in rat small diameter DRG neurons. Biochem. Biophys. Res. Commun. 452, 60-65. doi: 10.1016/j.bbrc.2014.08.051

Liu, Y. F., Ma, R. L., Wang, S. L., Duan, Z. Y., Zhang, J. H., Wu, L. J., et al. (2003). Expression of an antitumor-analgesic peptide from the venom of Chinese scorpion Buthus martensii karsch in Escherichia coli. Protein Expres. Purif. 27, 253-258. doi: 10.1016/S1046-5928(02)00609-5

Maingret, F., Coste, B., Padilla, F., Clerc, N., Crest, M., Korogod, S. M., et al. (2008). Inflammatory mediators increase Nav1.9 current and excitability in nociceptors through a coincident detection mechanism. J. Gen. Physiol. 131, 211-225. doi: 10.1085/jgp.200709935

Meymandi, M. S., and Keyhanfar, F. (2013). Assessment of the antinociceptive effects of pregabalin alone or in combination with morphine during acetic acid-induced writhing in mice. Pharmacol. Biochem. Behav. 110, 249-254. doi: 10.1016/j.pbb.2013.07.021

Munro, G. (2009). Pharmacological assessment of the rat formalin test utilizing the clinically used analgesic drugs gabapentin, lamotrigine, morphine, duloxetine, tramadol and ibuprofen: influence of low and high formalin concentrations. Eur. J. Pharmacol. 605, 95-102. doi: 10.1016/j.ejphar.2009.01.004

Ostman, J. A., Nassar, M. A., Wood, J. N., and Baker, M. D. (2008). GTP upregulated persistent $\mathrm{Na}+$ current and enhanced nociceptor excitability require NaV1.9. J. Physiol. 586, 1077-1087. doi: 10.1113/jphysiol.2007.147942

Payandeh, J., Scheuer, T., Zheng, N., and Catterall, W. A. (2011). The crystal structure of a voltage-gated sodium channel. Nature 475, 353-358. doi: 10.1038/ nature 10238

Possani, L. D., Merino, E., Corona, M., Bolivar, F., and Becerril, B. (2000). Peptides and genes coding for scorpion toxins that affect ion-channels. Biochimie 82, 861-868. doi: 10.1016/S0300-9084(00)01167-6

Priest, B. T., Murphy, B. A., Lindia, J. A., Diaz, C., Abbadie, C., Ritter, A. M., et al. (2005). Contribution of the tetrodotoxin-resistant voltage-gated sodium channel NaV1.9 to sensory transmission and nociceptive behavior. Proc. Natl. Acad. Sci. U.S.A. 102, 9382-9387. doi: 10.1073/pnas.0501549102

Quasthoff, S., Grosskreutz, J., Schroder, J. M., Schneider, U., and Grafe, P. (1995). Calcium potentials and tetrodotoxin-resistant sodium potentials in unmyelinated C fibres of biopsied human sural nerve. Neuroscience 69, 955965. doi: 10.1016/0306-4522(95)00307-5

Renganathan, M., Cummins, T. R., and Waxman, S. G. (2001). Contribution of $\mathrm{Na}(\mathrm{v}) 1.8$ sodium channels to action potential electrogenesis in DRG neurons. J. Neurophysiol. 86, 629-640.

Rosa, A. O., Egea, J., Lorrio, S., Rojo, A. I., Cuadrado, A., and Lopez, M. G. (2008). Nrf2-mediated haeme oxygenase-1 up-regulation induced by cobalt protoporphyrin has antinociceptive effects against inflammatory pain in the formalin test in mice. Pain 137, 332-339. doi: 10.1016/j.pain.2007. 09.015

Shields, S. D., Cavanaugh, D. J., Lee, H., Anderson, D. J., and Basbaum, A. I. (2010). Pain behavior in the formalin test persists after ablation of the great majority of C-fiber nociceptors. Pain 151, 422-429. doi: 10.1016/j.pain.2010. 08.001
Sleeper, A. A., Cummins, T. R., Dib-Hajj, S. D., Hormuzdiar, W., Tyrrell, L., Waxman, S. G., et al. (2000). Changes in expression of two tetrodotoxinresistant sodium channels and their currents in dorsal root ganglion neurons after sciatic nerve injury but not rhizotomy. J. Neurosci. 20, 7279-7289.

Staats, P. S., Yearwood, T., Charapata, S. G., Presley, R. W., Wallace, M. S., ByasSmith, M., et al. (2004). Intrathecal ziconotide in the treatment of refractory pain in patients with cancer or AIDS: a randomized controlled trial. JAMA 291, 63-70. doi: 10.1001/jama.291.1.63

Stix, G. (2005). A toxin against pain. Sci. Am. 292, 70-75. doi: 10.1038/scientificam erican0405-88

Tan, Z. Y., Xiao, H., Mao, X., Wang, C. Y., Zhao, Z. Q., and Ji, Y. H. (2001). The inhibitory effects of BmK IT2, a scorpion neurotoxin on rat nociceptive flexion reflex and a possible mechanism for modulating voltage-gated $\mathrm{Na}(+)$ channels. Neuropharmacology 40, 352-357. doi: 10.1016/S0028-3908(00)00168-4

Tsuzuki, K., Xing, H., Ling, J., and Gu, J. G. (2004). Menthol-induced Ca2+ release from presynaptic $\mathrm{Ca} 2+$ stores potentiates sensory synaptic transmission. J. Neurosci. 24, 762-771. doi: 10.1523/JNEUROSCI.4658-03.2004

Valdivia, H. H., Kirby, M. S., Lederer, W. J., and Coronado, R. (1992). Scorpion toxins targeted against the sarcoplasmic reticulum $\mathrm{Ca}(2+)$-release channel of skeletal and cardiac muscle. Proc. Natl. Acad. Sci. U.S.A. 89, 12185-12189. doi: 10.1073 /pnas.89.24.12185

Villarreal, C. F., Sachs, D., Cunha, F. Q., Parada, C. A., and Ferreira, S. H. (2005). The role of $\mathrm{Na}(\mathrm{V}) 1.8$ sodium channel in the maintenance of chronic inflammatory hypernociception. Neurosci. Lett. 386, 72-77. doi: 10.1016/j.neul et.2005.04.060

Yamamoto, T., Nozaki-Taguchi, N., and Chiba, T. (2002). Analgesic effect of intrathecally administered orexin-A in the rat formalin test and in the rat hot plate test. Br. J. Pharmacol. 137, 170-176. doi: 10.1038/sj.bjp.0704851

Yarotskyy, V., and Elmslie, K. S. (2009). Oemga-contoxin GVIA alters gating change movement of N-type(CaV2.2) calcium channels. J. Neurophysiol. 101, 322-340. doi: 10.1152/jn.91064.2008

Yu, Y. Q., Zhao, F., Guan, S. M., and Chen, J. (2011). Antisense-mediated knockdown of $\mathrm{Na}(\mathrm{V}) 1.8$, but not $\mathrm{Na}(\mathrm{V}) 1.9$, generates inhibitory effects on com plete Freund's adjuvant-induced inflammatory pain in rat. PLoS ONE 6:e19865. doi: 10.1371/journal.pone.0019865

Zimmermann, K., Leffler, A., Babes, A., Cendan, C. M., Carr, R. W., Kobayashi, J., et al. (2007). Sensory neuron sodium channel Nav1.8 is essential for pain at low temperatures. Nature 447, 855-858. doi: 10.1038/nature05880

Conflict of Interest Statement: The authors declare that the research was conducted in the absence of any commercial or financial relationships that could be construed as a potential conflict of interest.

Copyright (C) $2016 \mathrm{Li}$, Liu, Li, Ban, Chen, Cui, Zhang and Wu. This is an open-access article distributed under the terms of the Creative Commons Attribution License (CC BY). The use, distribution or reproduction in other forums is permitted, provided the original author(s) or licensor are credited and that the original publication in this journal is cited, in accordance with accepted academic practice. No use, distribution or reproduction is permitted which does not comply with these terms. 